Copyright (C) 2006 IEEE. Reprinted from

IEEE Transactions on Industry Applications, 2006; 42 (2):536-544

This material is posted here with permission of the IEEE. Such permission of the IEEE does not in any way imply IEEE endorsement of any of the University of Adelaide's products or services. Internal or personal use of this material is permitted. However, permission to reprint/republish this material for advertising or promotional purposes or for creating new collective works for resale or redistribution must be obtained from the IEEE by writing to pubs-permissions@ieee.org.

By choosing to view this document, you agree to all provisions of the copyright laws protecting it. 


\title{
Investigation of Inverterless Control of Interior Permanent-Magnet Alternators
}

\author{
Chong-Zhi Liaw, Student Member, IEEE, David M. Whaley, Student Member, IEEE, \\ Wen L. Soong, Member, IEEE, and Nesimi Ertugrul, Member, IEEE
}

\begin{abstract}
This paper investigates the performance and control of a low-cost 6-kW concept demonstrator of an "inverterless" automotive alternator. This is based on a switched-mode rectifier (SMR) combined with a high-flux interior permanent-magnet (PM) machine. Duty cycle control of the SMR is described and the theoretical predictions are compared with open-loop experimental results. The efficiency of the concept demonstrator is examined as a function of speed and load. Control issues regarding automotive operation are discussed.
\end{abstract}

Index Terms-Alternator, interior permanent-magnet (PM) machine, inverterless, switched-mode rectifier.

\section{INTRODUCTION}

$\mathbf{I}$ NCREASING automotive electrical loads have created a demand for low-cost high-power alternators. An example specification for such an alternator is an output power requirement of $4 \mathrm{~kW}$ at an engine speed of $600 \mathrm{r} / \mathrm{min}$ and $6 \mathrm{~kW}$ at $6000 \mathrm{r} / \mathrm{min}$ [1]. This is illustrated in Fig. 1 assuming a 3:1 belt ratio between the alternator and engine giving an alternator speed range of $1800-18000 \mathrm{r} / \mathrm{min}$.

The conventional wound-field Lundell alternator is relatively cheap, at about US $\$ 75$, but is only capable of producing $1-2 \mathrm{~kW}$ of output power.

Inverter-driven alternators have been proposed to meet the high-power alternator requirements. These include induction, switched reluctance, surface permanent-magnet (PM), and interior PM machines. Unfortunately, these solutions are expensive, costing in excess of US $\$ 500$ with much of the cost due to the power electronics and the control complexity [1].

Previous studies by Perreault and Caliskan [2], Rivas et al. [3], and Whaley et al. [9] have investigated means for extracting greater output power from the existing Lundell alternator using a switched-mode rectifier (SMR) (see Fig. 1). Compared to an inverter, the SMR offers simpler control and uses fewer switches but has a reduced output power at low speeds as it can only operate the machine at unity power factor. Inverters are able to create a leading power factor and are able

Paper IPCSD-05-083, presented at the 2004 Industry Applications Society Annual Meeting, Seattle, WA, October 3-7 and approved for publication in the IEEE TRANSACTIONS ON INDUSTRY APPLICATIONS by the Industrial Drives Committee of the IEEE Industry Applications Society. Manuscript submitted for review September 11, 2004 and released for publication November 25, 2005. This work was supported by Australian Research Council Discovery Grant DP0342874.

The authors are with the Electrical and Electronic Engineering Department, University of Adelaide, Adelaide, SA 5005, Australia (e-mail: chongzhi@ eleceng.adelaide.edu.au; dwhaley@eleceng.adelaide.edu.au; wen.soong@ adelaide.edu.au; nesimi.ertugrul@adelaide.edu.au).

Digital Object Identifier 10.1109/TIA.2005.863910

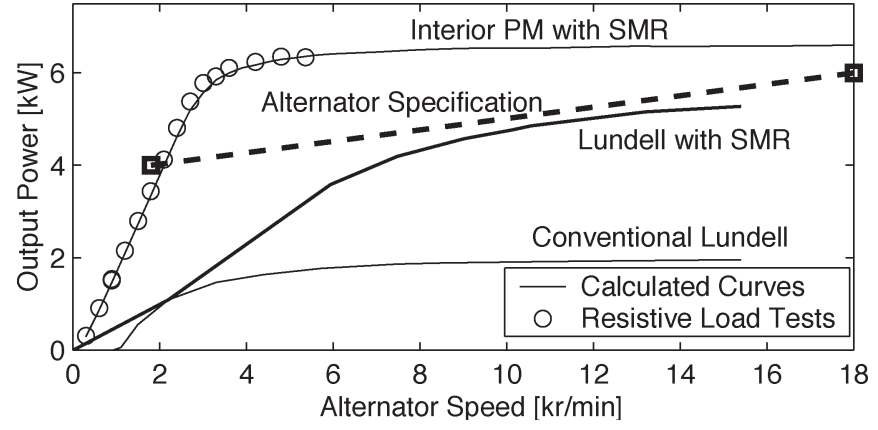

Fig. 1. High-power alternator specification and the calculated output power versus speed curves of a conventional Lundell alternator, and the Lundell and interior PM alternators with an SMR.

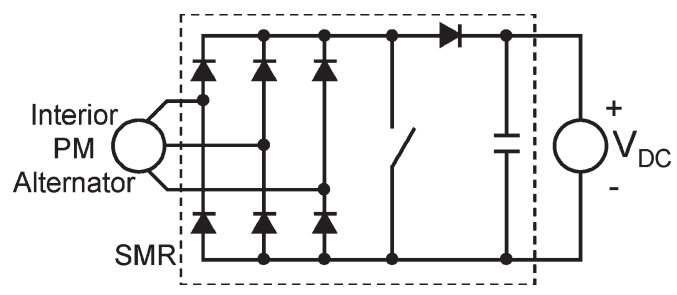

Fig. 2. Circuit diagram of the inverterless (SMR) configuration.

to extract roughly twice the output power from the machine at low speeds [4].

Recent work by Soong and Ertugrul [4] has proposed operating an SMR with a high-saliency high-flux interior PM alternator. This was called an "inverterless" configuration (see Fig. 2) as interior PM machines are normally operated with inverters. This earlier work analyzed the inverterless performance of interior PM machines but showed only limited experimental results from a 6-kW interior PM alternator using a three-phase resistive load to simulate the SMR (see circles in Fig. 1). These results showed the potential to meet the high-power alternator specification.

However, high-frequency switching, discontinuous waveforms, and other losses caused by an SMR may have effects that are not reflected in the three-phase resistive load results. Thus, this paper follows on from the previous work by investigating the performance and control of the 6-kW interior PM alternator with an actual SMR.

The layout of the paper is given as follows. The operation of the SMR is explained in Section II. The interior PM alternator and its parameters are described in Section III. Steady-state open-loop results showing the output power capability and efficiency of the interior PM alternator and SMR as a function 


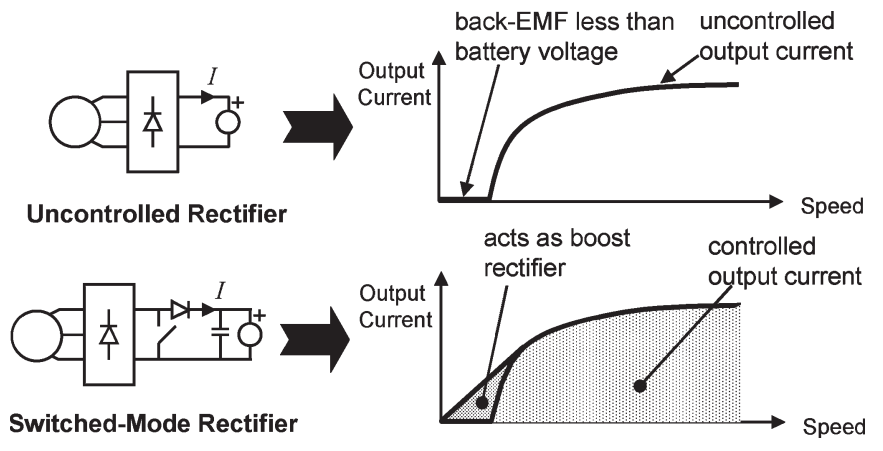

Fig. 3. Comparison of the operation of an uncontrolled rectifier and an SMR.

of speed and duty cycle are given in Section IV. Finally, closedloop control issues such as maximizing the output power and regulating the output voltage are discussed in Section V.

\section{SMR OPERATION}

One implementation of an SMR (see Fig. 2) consists of a three-phase rectifier, a single controlled switch, and a diode. SMR operation involves the rapid switching of the dc output of the rectifier between the load and ground by a pulsewidthmodulated (PWM) control signal. With a high switching frequency and sufficiently large machine inductance, the alternator sees only the time-averaged effect of the PWM switching.

In describing the action of the SMR, it is useful to contrast the operation of an interior PM alternator generating into a vehicle battery (modeled as a voltage source load) via an SMR versus an uncontrolled rectifier.

\section{A. Uncontrolled Rectifier Operation}

In the case of an uncontrolled rectifier, the alternator operates in uncontrolled generation (UCG) [5], [6]. As the speed increases from standstill, the dc output current remains at zero up to the speed at which the rectified back electromotive force (EMF) equals the dc-link (battery) voltage (see Fig. 3). Beyond that speed, the output current rises rapidly and asymptotes towards a maximum value that is equal to the machine's magnet flux linkage, $\Psi_{\text {mag }}$, divided by the $d$-axis inductance, $L_{d}$ [5]. At high speeds, the back EMF is much higher than the output voltage, and, hence, the output of the three-phase rectifier resembles a dc constant current source that is independent of speed.

\section{B. SMR Operation}

An SMR modifies the alternator output power characteristic in two ways. First, at high speeds, where the alternator resembles a dc constant current source $I_{\mathrm{IN}}$, the duty cycle $d$ of the switch sets the fraction of the input current which is delivered to the load versus that which flows through the switch to ground. The dc output current $I_{\mathrm{OUT}}$ is thus equal to $(1-d) I_{\mathrm{IN}}$. This method allows the output power to be controlled between zero and a maximum value and is the basis for output voltage regulation (see Fig. 4).

Second, at low alternator speeds, the induced back EMF is smaller than the dc-link voltage. While the SMR switch is on,
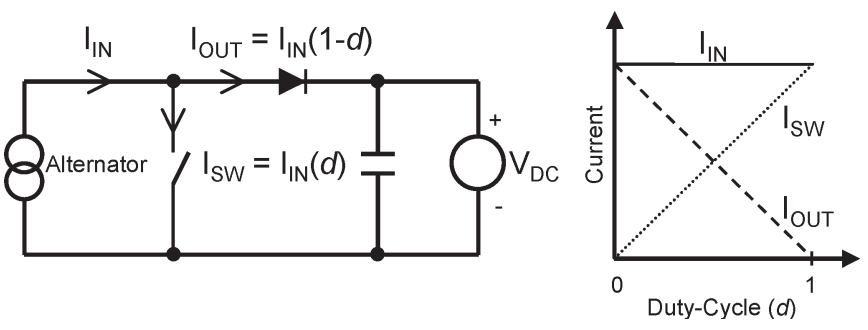

Fig. 4. Output current control of the SMR at high speeds by varying the duty cycle with the alternator operating as a constant current source.

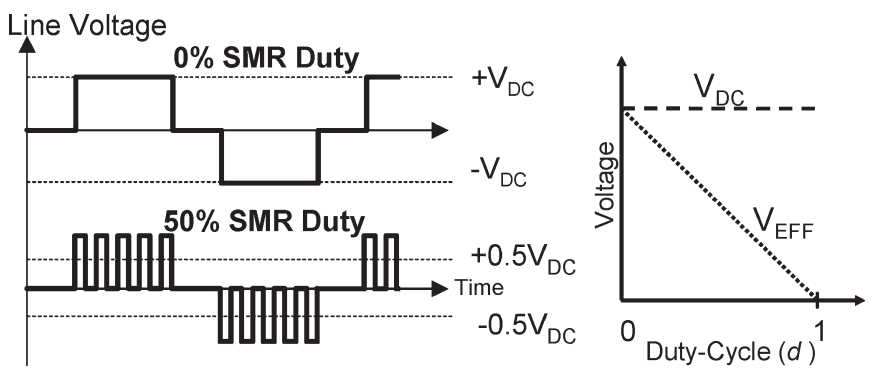

Fig. 5. Effect of SMR operation on the alternator stator line voltage waveform
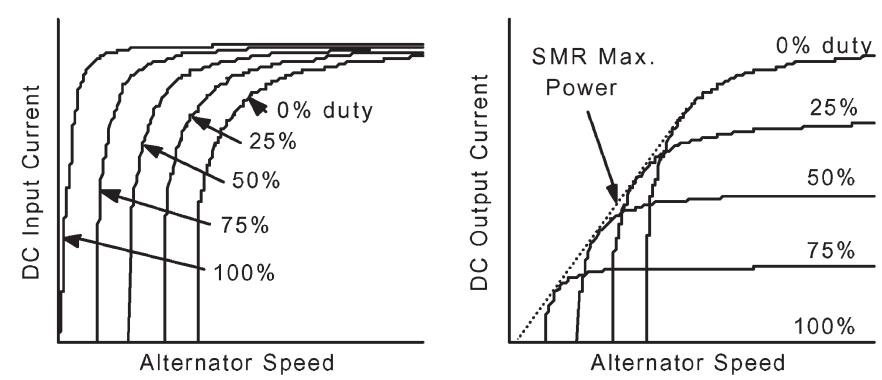

Fig. 6. DC input and dc output current versus alternator speed while generating into a voltage-source load for various duty cycles.

the alternator windings are short circuited and the input current increases linearly. When the switch opens, the inductance of the machine windings forces the current into the dc link despite the dc link voltage being higher than the machine back EMF. In this manner, the SMR acts as a boost rectifier and allows power to be generated at low speeds. This can also be thought of as the SMR reducing the effective dc-link voltage seen by the alternator to $V_{\mathrm{EFF}}=(1-d) V_{\mathrm{dc}}$. For instance, in Fig. 5, it can be seen that increasing the duty cycle from $0 \%$ to $50 \%$ decreases the effective dc-link voltage seen by the machine from $V_{\mathrm{dc}}$ to $0.5 V_{\mathrm{dc}}$.

The graphs of Fig. 6 illustrate how the two modes of operation mentioned affect the input and output current versus characteristics of the alternator.

For a given value of duty cycle $d$, the output current curve is similar to that for UCG (see top half of Fig. 3) where the effective alternator dc link voltage is $V_{\mathrm{EFF}}=(1-d) V_{\mathrm{dc}}$. It also shows how increasing the duty cycle reduces the effective dc-link voltage and, hence, reduces the minimum speed for output power generation.

At any particular speed, the alternator output power depends on the effective alternator output voltage and hence the duty cycle. The right-hand graph of Fig. 6 shows how the duty cycle 
TABLE I

INTERIOR PM ALTERNATOR PARAMETERS

\begin{tabular}{|l|c|}
\hline Machine Parameter & Value \\
\hline pole-pairs & 2 \\
\hline q-axis inductance (mH) (unsat) & 36.2 \\
\hline d-axis inductance $(\mathrm{mH})$ (sat) & 6.15 \\
\hline phase resistance (ohms) & 0.77 \\
\hline saliency ratio (max) & 6 \\
\hline line-to-line back-EMF at 1500 r/min (Vrms) & 92.4 \\
\hline short-circuit current at 1500 r/min (A) & 26.9 \\
\hline magnet flux (Wb peak) & 0.240 \\
\hline
\end{tabular}

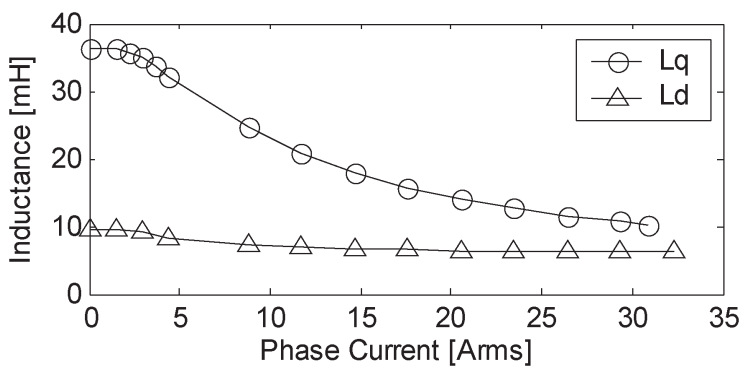

Fig. 7. $d$-axis and $q$-axis inductance saturation curves for the interior PM alternator.

corresponding to maximum output power decreases with increasing speed until it reaches $0 \%$ (dashed line). This maximum output current curve matches that shown in Fig. 3. At high speeds, the input current is relatively constant and the dc output current $I_{\mathrm{OUT}}$ is then given by $(1-d) I_{\mathrm{IN}}$, i.e., applying a $50 \%$ duty cycle reduces the output current by half.

In summary, the SMR allows the alternator to produce output power at low speeds by acting as a boost rectifier. It also allows the output current at all speeds to be controlled by the duty cycle of the switch (see Fig. 6). At any particular operating speed, the duty cycle can be adjusted so that the load is matched to the machine, allowing maximum power transfer [2]. The following sections investigate the control of a prototype interior PM alternator in an experimental test arrangement using the above principles of SMR operation.

\section{EXPERIMENTAL SETUP AND MACHINE CHARACTERISTICS}

This section describes the interior PM alternator and the dynamometer arrangement. It also compares the calculated versus measured alternator performance when operated with a three-phase rectifier and resistive load, and also under shortcircuit conditions.

\section{A. Interior PM Alternator}

The alternator used was a multiple-barrier interior PM machine with rare-earth $(\mathrm{NdFeB})$ magnets that was described in [4]. This machine was specifically designed for both high back EMF and high inductance, and has a rated current equal to the short-circuit current. These characteristics give it a high output power and a wide constant power speed range.

The machine parameters and inductance curves are shown in Table I and Fig. 7. The previous results from this machine were taken with a $415-\mathrm{V}$ stator. A $135-\mathrm{V}$ stator was used for the

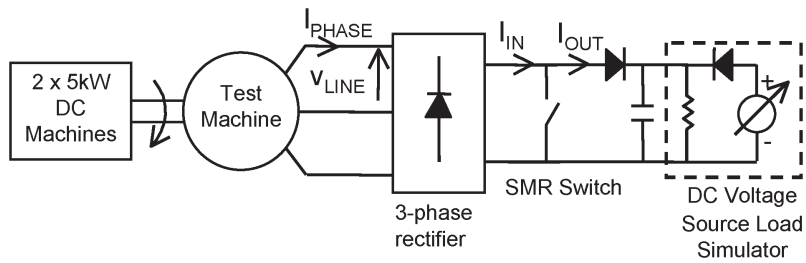

Fig. 8. Inverterless alternator test rig block diagram.
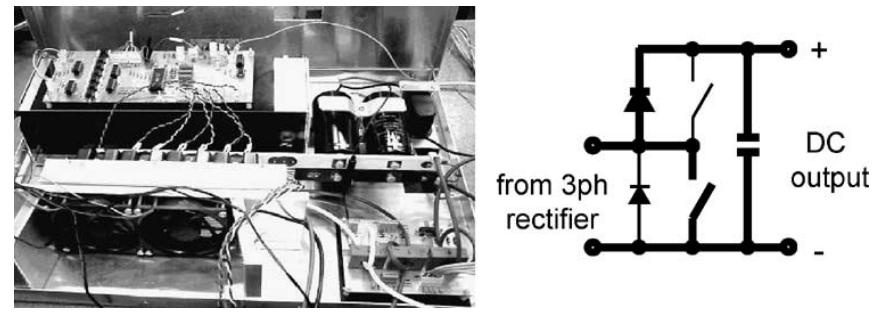

Fig. 9. Power electronics unit used for the SMR and circuit diagram of one phase leg showing the switch and diode used (bold lines).

SMR tests to match the rating of the available power electronics unit. As the 415- and 135-V stators were identical apart from a reduction in the number of turns, the inductance saturation curves in Fig. 7 for the 135-V stator were obtained by scaling the measured $415-\mathrm{V}$ stator's inductance curves.

A steady-state model making use of the measured machine parameters and inductance curves was used to generate the predicted voltage-current and voltage-power loci described in Section III-C. This model assumes that the rectifier and voltage source load can be approximated by a three-phase resistive load [7] and solves the $d / q$ model equations to obtain the voltage-current locus. The model also incorporates the effects of magnetic saturation and stator resistance. A full description of the model is given in [6].

\section{B. Inverterless Test Arrangement}

Experimental results were obtained using the test rig shown in Fig. 8. The output of the interior PM test machine was fed through an SMR into a $200-\mathrm{V}$ dc voltage source load. This load maintains a constant SMR output voltage despite variations in the output current of the SMR. It was implemented using a dc power supply, protective diode, and a load resistance bank (see dashed box in Fig. 8).

Fig. 9 shows a photograph of the power electronics unit used for the SMR. It is based on an existing 200-V 50-A three-phase inverter. The alternator was connected to an external threephase rectifier and the output of the rectifier was connected to the "output" of one phase leg of the inverter. The lower switch of the phase leg was used as the controlled switch and the freewheeling diode of the upper switch was used to allow power to flow through the dc link of the inverter to the load.

\section{Alternator Voltage-Current Curves}

The steady-state alternator model described above is based on assuming a three-phase resistive load. The calculated results from this model show a good correspondence with the 

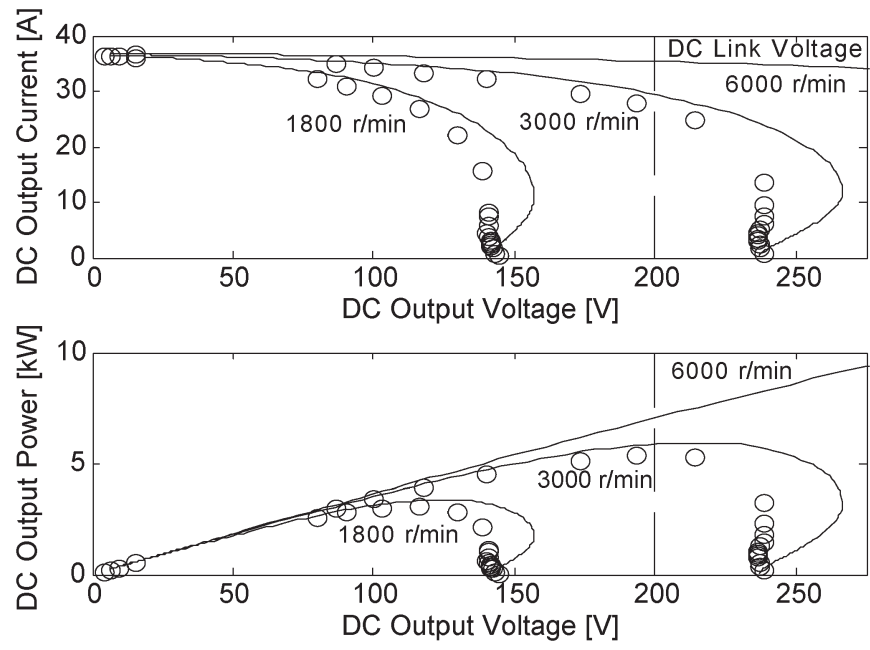

Fig. 10. Alternator output dc voltage-current and dc voltage-power curves at 1800,3000 , and $6000 \mathrm{r} / \mathrm{min}$. Calculated results (lines) and measured points for 1800 and $3000 \mathrm{r} / \mathrm{min}$ (circles).

experimental results of the alternator when tested with a threephase resistive load (see Fig. 1).

Fig. 10 shows a comparison of the calculated results with the experimental results obtained by running the alternator into a three-phase rectifier and resistive load. It shows the measured and calculated voltage-current and voltage-power curves for the alternator at various speeds. The dashed vertical line represents a dc link output voltage of $200 \mathrm{~V}$. This dc-link voltage was chosen as it corresponds approximately to the alternator rated line voltage $(135 \mathrm{~V})$. When operating with a $200-\mathrm{V}$ dc output voltage at $3000 \mathrm{r} / \mathrm{min}$, the alternator can produce around $5 \mathrm{~kW}$ of output power.

At low dc-link voltages, the rectified back EMF is much greater than the dc-link voltage and so, as indicated in Section II, the alternator output current is constant and does not vary with speed. Thus, in this region, the alternator acts as a constant current source and the output power increases linearly with the dc output voltage. The measured results show a close correspondence with the calculated results in this region.

At dc-link voltages comparable to the rectified back EMF, the calculated curves show a voltage "overshoot" effect where the voltage under load is greater than the open-circuit voltage [6]. The significant discrepancy with the measured results in this part of the curve is likely due to the discontinuous current waveforms in this region [6], resulting in a breakdown of the model assumptions.

\section{Short-Circuit Test Results}

A short-circuit test was performed to verify that the steadystate model accurately predicts the behavior of the interior PM machine. The machine was run with its stator windings shorted. The resulting short-circuit current rises monotonically with speed until it reaches a maximum value of $\Psi_{\mathrm{mag}} / L_{d}$ (see Fig. 11). The torque reaches a maximum at a low speed (about $200 \mathrm{r} / \mathrm{min}$ ) and then gradually decreases with increasing speed. The measured results match well with the model predictions.
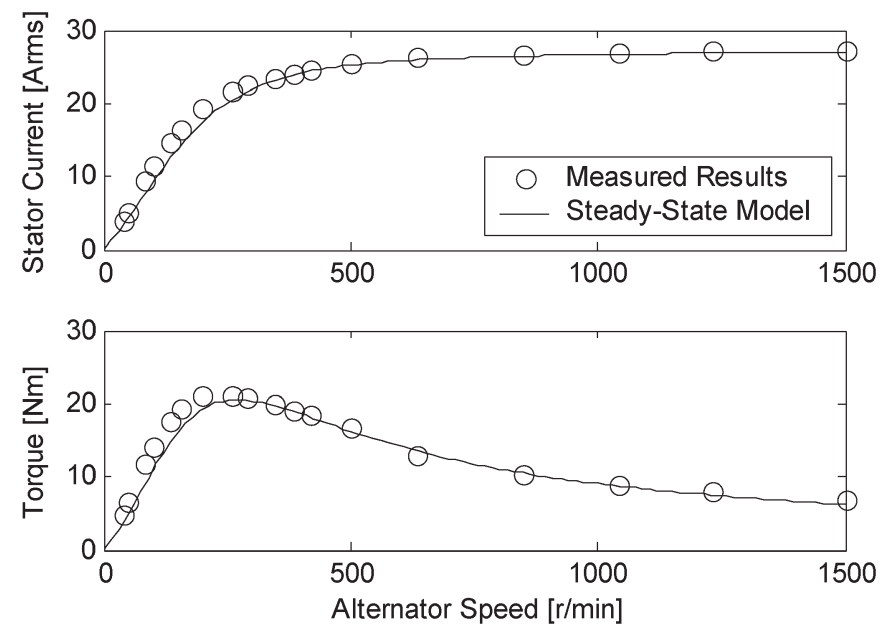

Fig. 11. Alternator short-circuit current and torque, versus speed.

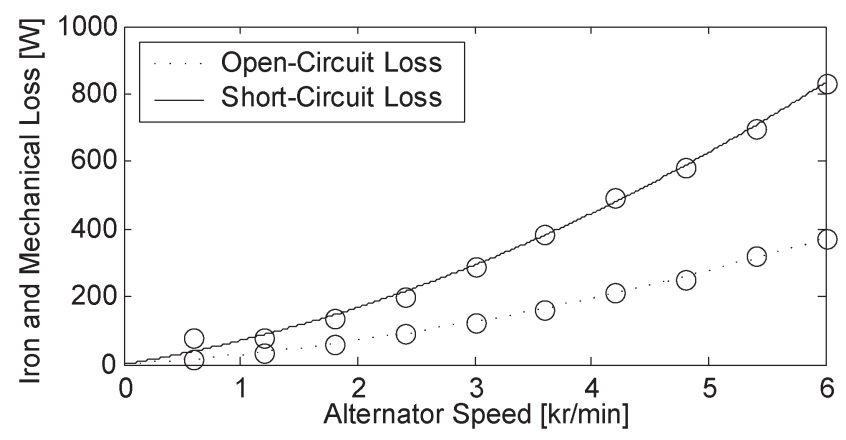

Fig. 12. Measured (circles) and fitted (lines) alternator iron and mechanical losses, under open-circuit and short-circuit conditions.

\section{E. Iron and Mechanical Losses Under Short-Circuit and Open-Circuit Conditions}

The open-circuit and short-circuit iron and mechanical losses of the interior PM machine were measured (see Fig. 12). The open-circuit iron and mechanical losses were obtained from the input mechanical power measurements under open-circuit conditions. The iron and mechanical losses under short-circuit conditions were obtained by subtracting the measured stator copper loss from the input mechanical power results calculated from the input torque shown in Fig. 11.

The machine shows a significant increase in iron losses under short-circuit (i.e., field weakening) conditions. Finite-element investigations [8] have shown that this is likely to be due to large amplitude harmonic air-gap flux density components during field weakening. These losses are roughly proportional to the square of speed. At $6000 \mathrm{r} / \mathrm{min}$, the short-circuit iron losses are around $800 \mathrm{~W}$. Extrapolating the short-circuit loss gives a very high predicted loss of $5.4 \mathrm{~kW}$ at $18000 \mathrm{r} / \mathrm{min}$.

The high iron loss in the concept demonstrator interior PM machine is due to the high frequency of operation $(600-\mathrm{Hz}$ fundamental at $18000 \mathrm{r} / \mathrm{min}$ ) and high magnet flux from the rare-earth magnets. Note that the machine stator is from a lowcost commercial $50-\mathrm{Hz}$ induction machine. It is expected that the iron loss can be reduced to more reasonable values by the use of thinner lower loss lamination material and by optimizing 


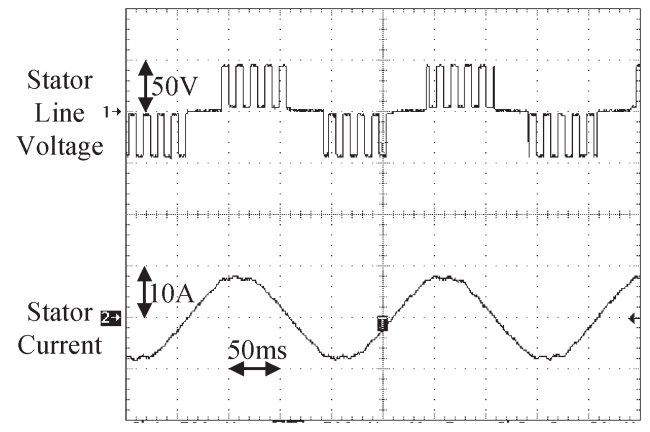

Fig. 13. Typical measured waveforms showing 50\% duty cycle SMR switching on the stator voltage and stator current. The SMR switching frequency was reduced from $4 \mathrm{kHz}$ to $800 \mathrm{~Hz}$ for display purposes.

the electromagnetic design to minimize the harmonic air-gap flux components during field weakening.

\section{OPEN-LOOP SMR TEST RESUlTS}

This section describes test results obtained from the alternator and SMR operating into a constant voltage source load as shown earlier in Fig. 8. The steady-state response of the alternator output power and efficiency at various speeds and duty cycles are examined.

\section{A. Voltage and Current Waveforms}

Typical stator voltage and current waveforms of the alternator while operating with the SMR were recorded and are shown in Fig. 13. The voltage waveform matches the ideal result shown earlier in Fig. 5. Although the stator voltage shows the pulsewidth modulation action of the SMR, the high-frequency switching transients are filtered by the large inductance of the alternator, so that the stator current remains sinusoidal.

\section{B. Current Versus Duty Cycle Performance at Different Speeds}

The interior PM alternator with an SMR was connected in the configuration shown in Fig. 8 with a $200-\mathrm{V}$ dc voltage source load.

Fig. 14 shows the dc input and output current of the switch as the duty cycle is varied. Experimental points are plotted against the model predictions for various speeds. The results confirm the relationship described earlier in Section II that at high speeds and/or high values of duty cycle, the switch input current $I_{\mathrm{IN}}$ is constant and that the switch output current $I_{\mathrm{OUT}}$ equals $(1-d) I_{\mathrm{IN}}$.

As the duty cycle $d$ controls the effective de link voltage $V_{\mathrm{EFF}}=(1-d) V_{\mathrm{dc}}$, these graphs are similar to those in Fig. 10 for the alternator with a rectifier/resistive load where the dc output voltage is varied. The effective dc-link voltage is proportional to $(1-d)$, and, hence, the $x$-axis is reversed between the two figures. Note that the dc input current to the switch in Fig. 14 corresponds to the rectified dc output current of the alternator in Fig. 10, and that as the SMR dc link voltage is constant, the dc output current in Fig. 14 corresponds to the output power of the alternator in Fig. 10.

The measured results are close to the predictions, but generation starts at a higher duty cycle and hence lower effective
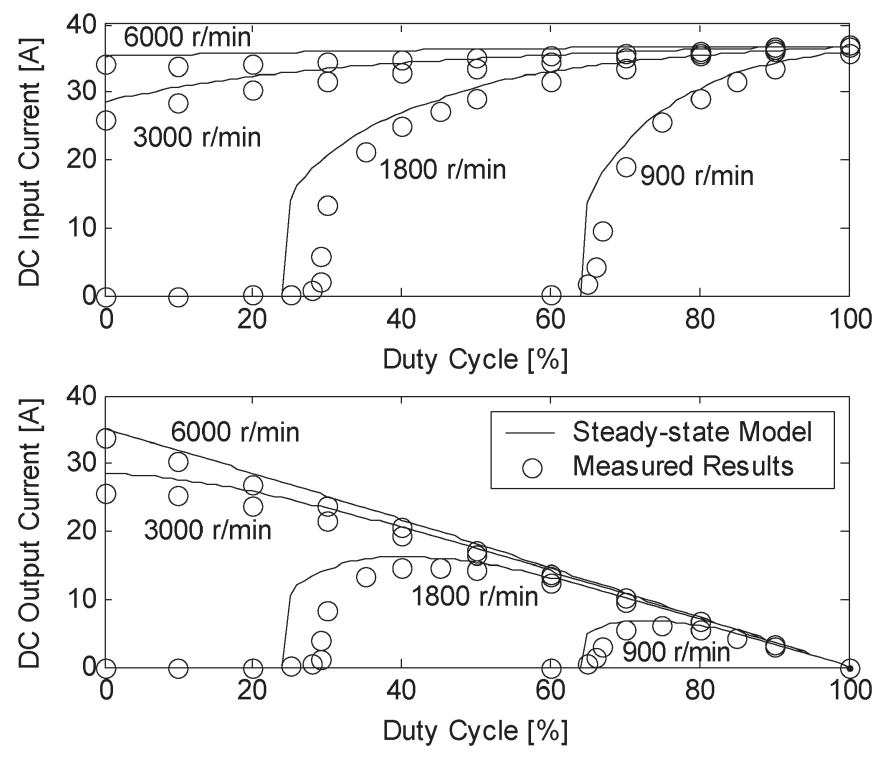

Fig. 14. Switch dc input and output currents versus duty cycle at various speeds, with a $200-\mathrm{V}$ dc-link voltage. The model used a dc-link voltage of $205 \mathrm{~V}$ to allow for device voltage drops.

dc link voltage than predicted. This suggests that there are additional voltage drops in the system.

At the lower speeds of 900 and $1800 \mathrm{r} / \mathrm{min}$, the output power falls to zero below a certain minimum duty cycle. This is because below this duty cycle, the effective dc-link voltage $(1-d) V_{\mathrm{dc}}$ is greater than the back EMF voltage at this speed. At higher speeds, the back EMF is greater than the actual dclink voltage $V_{\mathrm{dc}}$, resulting in power output obtained for all values of duty cycle.

At $6000 \mathrm{r} / \mathrm{min}$, the dc input current is relatively constant at around $35 \mathrm{~A}$ over the entire duty cycle range, while the output current shows the expected $(1-d)$ relationship. The maximum dc output current achieved is $34 \mathrm{~A}$, which with the $200-\mathrm{V} \mathrm{dc}-$ link voltage, corresponds to an output power of $6.8 \mathrm{~kW}$.

As indicated in Section II, the output current of the SMR is linearly proportional to $(1-d)$ and is independent of speed.

Fig. 15 shows the efficiency of the inverterless alternator as a function of output power for various speeds, obtained from the test results shown in Fig. 14. The steady-state model predictions shown in Fig. 15 do not include iron loss and so show an error that increases with speed.

Fig. 16 shows the steady-state model predictions including iron losses (based on the measured short-circuit iron losses versus speed results shown in Fig. 12). This shows a greatly improved correspondence between the calculated and measured results.

The alternator efficiency is poor at light loads but improves rapidly with increasing load. The maximum efficiency obtained is around $85 \%$ at $3000 \mathrm{r} / \mathrm{min}$ and $82 \%$ at $1800 \mathrm{r} / \mathrm{min}$. At $6000 \mathrm{r} / \mathrm{min}$, the efficiency is about $75 \%$ at an output power of $6 \mathrm{~kW}$. The efficiency at light loads is generally higher if the alternator is running at lower speeds due to the lower iron losses.

The poor light load efficiency is inherent in the inverterless concept. This is due to the high stator currents and, hence, high copper losses under all operating conditions including light loads. The light load efficiency can be improved by oversizing 


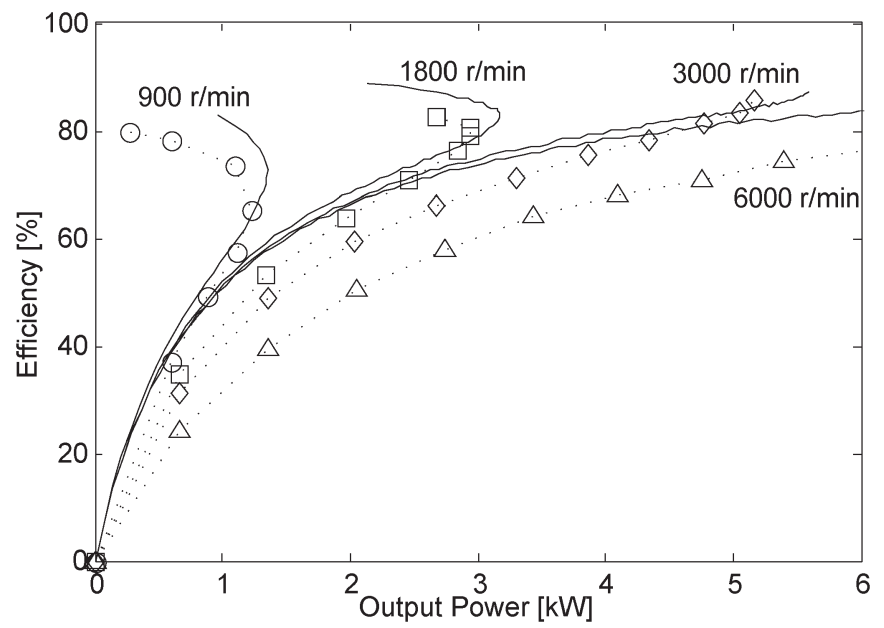

Fig. 15. Inverterless alternator efficiency versus dc output power for various alternator speeds, showing steady-state model predictions without iron loss (solid lines) and measured results (dashed lines).

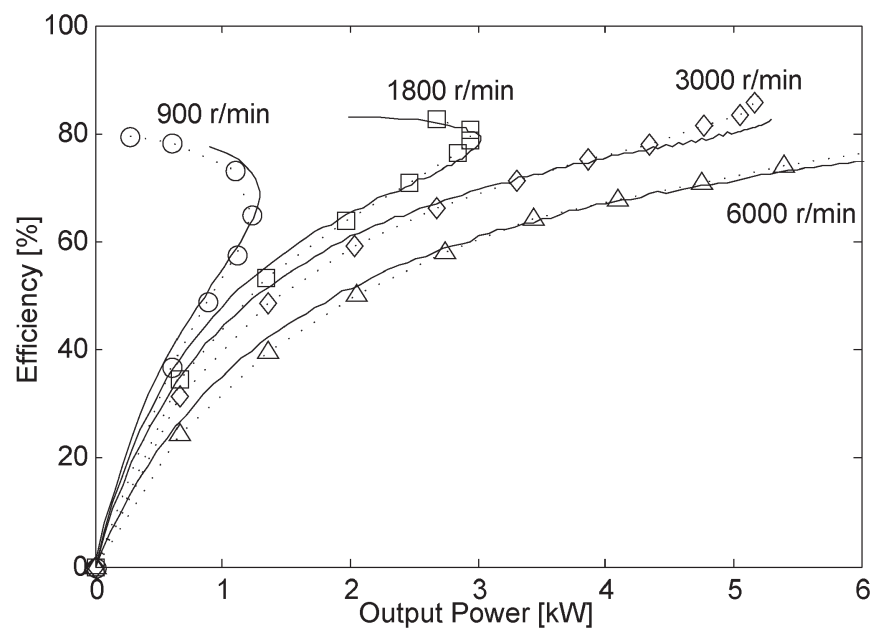

Fig. 16. Inverterless alternator efficiency versus dc output power for various alternator speeds, showing steady-state model predictions with iron loss (solid lines) and measured results (dashed lines).

the alternator to reduce the stator resistance and, hence, the copper losses. Reducing the stator resistance increases the lowspeed output power slightly and has no effect on the high speed output power.

At lower speeds, higher efficiency can be achieved by operating in the "nonlinear" region of the curve, that is, using a duty cycle that is less than the duty cycle at which maximum output power is obtained. For instance, at $900 \mathrm{r} / \mathrm{min}$, it is possible to obtain $80 \%$ efficiency at $500 \mathrm{~W}$. The higher efficiency is due to the lower stator currents and, hence, copper losses in this condition. The disadvantage of this approach is that it causes greater control complexity due to the sensitivity to the operating speed.

\section{Maximum Output Power as a Function of Speed}

The maximum generating power of the inverterless alternator system as a function of speed is shown in Fig. 17 for a $200-\mathrm{V}$ dc-link voltage. At each speed, the duty cycle was adjusted to maximize the output power.
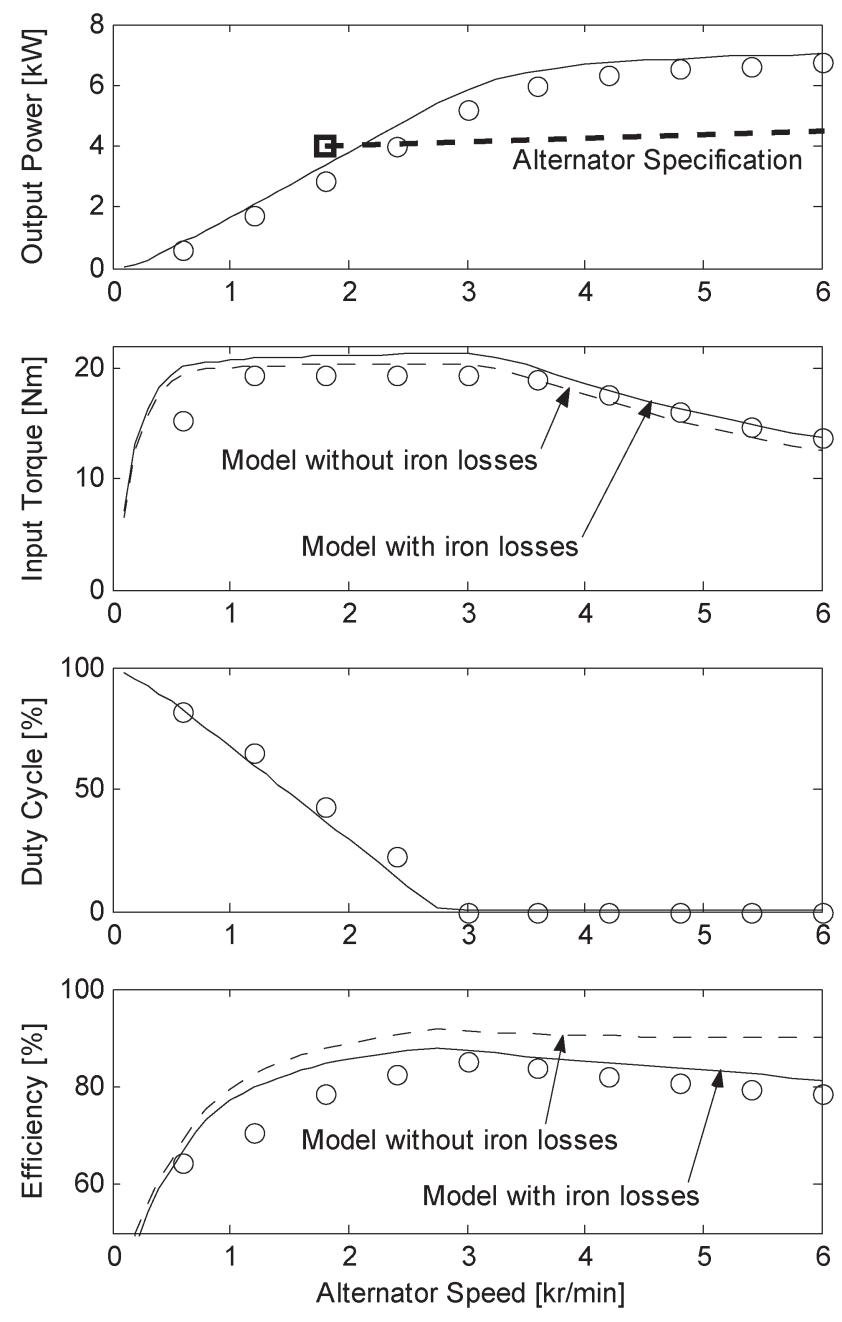

Fig. 17. Alternator maximum generating output power, input torque, duty cycle, and efficiency versus speed, showing steady-state model predictions (lines) and measured results (circles), for a $200-\mathrm{V}$ dc-link voltage.

The output power increases linearly from standstill up to about $3000 \mathrm{r} / \mathrm{min}$, after which the output power remains relatively constant. Below this speed, the SMR is acting as a boost rectifier, applying a nonzero duty cycle to match the alternator output voltage to the higher dc-link voltage.

At $6000 \mathrm{r} / \mathrm{min}$, the maximum output power obtained is around $6.6 \mathrm{~kW}$, with an efficiency of $80 \%$. The output power at engine idle $(1800 \mathrm{r} / \mathrm{min}$ at the alternator assuming a $3: 1$ belt ratio) is $2.8 \mathrm{~kW}$, which is significantly below the $4-\mathrm{kW}$ high-power alternator specification (shown as a dashed line). Whereas the earlier power measurements taken with a threephase resistive load [4] shown in Fig. 1 match the steadystate model predictions very closely, it can be seen that the measured output power with the SMR is slightly lower due to the additional losses.

Fig. 17 shows the model predictions both with iron losses (solid lines) and without iron losses (dashed lines). Iron losses do not affect the electrical output power but increase the required input torque, thus decreasing the system efficiency. The measured results show a good correspondence to the steadystate model predictions with iron loss. 


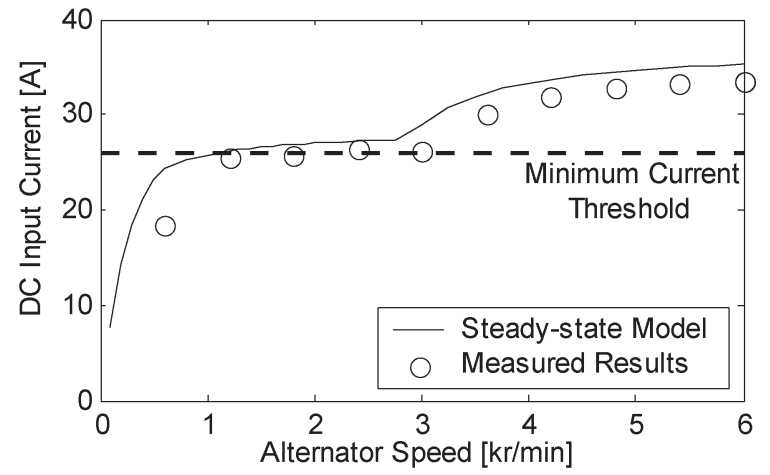

Fig. 18. DC input current corresponding to maximum power, versus alternator speed, for a $200-\mathrm{V}$ dc-link voltage.

\section{Closed-Loop Control Discussion}

This section describes some of the control issues associated with applying the inverterless alternator to an automotive application. These include maximizing the output power at low speeds and regulating the output voltage under steady-state and dynamic conditions.

\section{A. Maintaining Maximum Output Power at Low Speeds}

At any given speed, the alternator operates along the respective output current versus duty cycle curve (see Fig. 14). Between 3000-6000 r/min, the output current varies roughly linearly with duty cycle (see Fig. 19) and the duty cycle may range anywhere from $100 \%$, where no current is delivered to the load, to $0 \%$, where maximum current is delivered.

However, at speeds below $3000 \mathrm{r} / \mathrm{min}$, there is a minimum duty cycle below which generation does not occur as the effective dc-link voltage is higher than the machine back EMF. There is also a particular duty cycle that delivers maximum output current and, hence, output power. At low speeds, the minimum allowable value of the duty cycle should be limited to the value corresponding to maximum output power.

Two methods are proposed for keeping the controller from reducing the duty cycle past the maximum output power point at low speeds.

First, if the alternator speed can be monitored, then the minimum allowable duty cycle as a function of speed is a simple linear function as shown by the duty cycle plot in Fig. 17. The simplest means for monitoring the alternator speed is to measure the electrical frequency of the stator currents [3].

A second method utilizes measuring the dc input current to the switch. When the alternator is delivering maximum output power, the input current is roughly constant and does not vary significantly with speed. From the 900 - and $1800-\mathrm{r} / \mathrm{min}$ curves in Fig. 14, the current corresponding to maximum power is about 26 A. At no load (100\% duty cycle), the input current at these speeds is about $36 \mathrm{~A}$. Thus, the usable operating range of the input current is from 26 to $36 \mathrm{~A}$.

Fig. 18 shows the calculated and measured dc input current corresponding to the maximum output power results in Fig. 17. For speeds from 1000 to $3000 \mathrm{r} / \mathrm{min}$, the dc input current is roughly constant as the alternator operates at the maximum output power point. Above $3000 \mathrm{r} / \mathrm{min}$, the maximum output

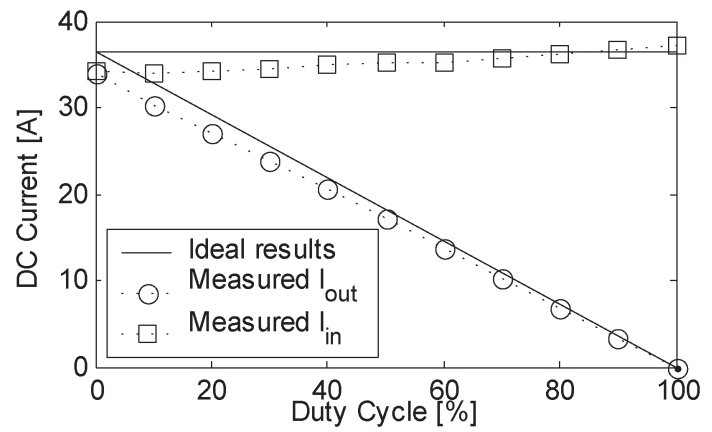

Fig. 19. DC input and dc output current from the SMR, versus duty cycle at $6000 \mathrm{r} / \mathrm{min}$. The ideal results assume that the input current is independent of duty cycle.

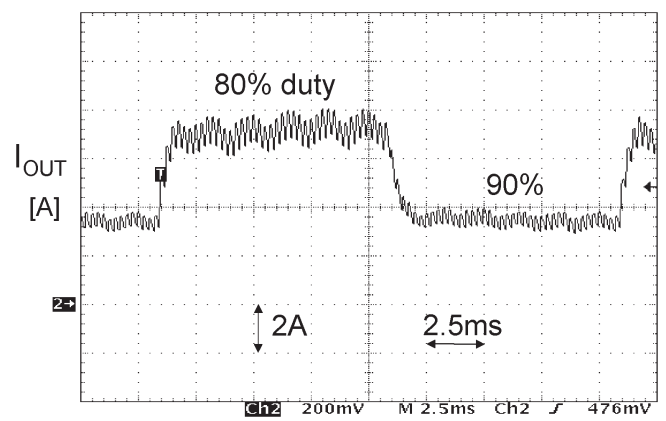

Fig. 20. Dynamic response of the dc output current to step changes in switching duty cycle at $1800 \mathrm{r} / \mathrm{min}$.

power point occurs for de link voltages greater than $200 \mathrm{~V}$, and, hence, the duty cycle for maximum power is $0 \%$. This causes the dc input current corresponding to maximum power to increase as a function of speed.

Fig. 18 suggests that a possible method for maintaining maximum output power at low speeds is to monitor the input dc current and to keep it above $26 \mathrm{~A}$. This method is valid for speeds above $1000 \mathrm{r} / \mathrm{min}$. This is acceptable since automotive alternators typically have an idle speed of around $1800 \mathrm{r} / \mathrm{min}$ (engine idle of $600 \mathrm{r} / \mathrm{min} \times 3: 1$ belt drive ratio).

\section{B. Output Voltage Regulation}

The results from previous sections have shown that for sufficiently high speeds, the output current of the SMR is linearly proportional to $(1-d)$. Output voltage regulation can thus be achieved by controlling the SMR duty cycle to obtain the appropriate output current. Fig. 19 shows the dc input current and dc output current at $6000 \mathrm{r} / \mathrm{min}$.

\section{Dynamic Response to Changing Duty Cycle}

The dynamic response of the machine to duty cycle changes was investigated by applying a periodic step change to the duty cycle with the alternator running at $1800 \mathrm{r} / \mathrm{min}$. The resulting dc output current is shown in Fig. 20. The current waveform is modulated by a higher frequency oscillation of $4 \mathrm{kHz}$ caused by the SMR switching. A lower frequency oscillation is associated with the ripple found in a typical rectified current waveform from a three-phase bridge rectifier. 


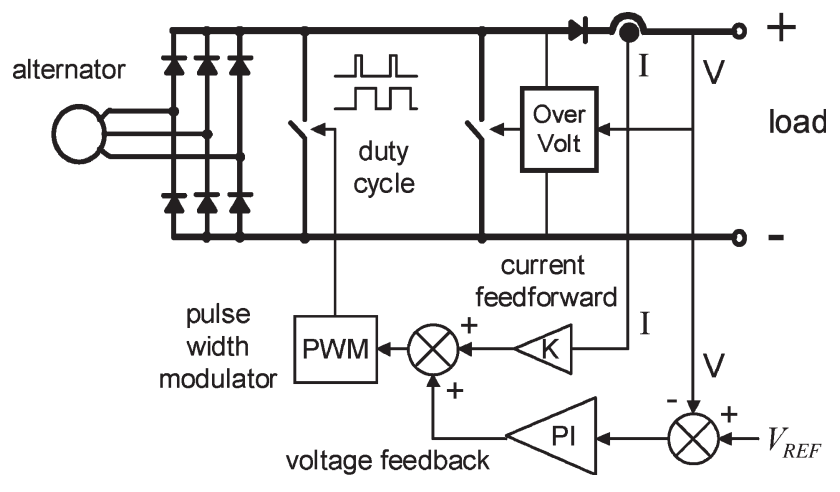

Fig. 21. Block diagram of a possible inverterless alternator control system.

As the duty cycle changes from $80 \%$ to $90 \%$, the output current changes from 7.2 to $3.6 \mathrm{~A}$, respectively. These values match the steady-state model predictions of Fig. 14. The rise and fall times of the current response were approximately $1 \mathrm{~ms}$, and this time constant was used in forming an s-domain transfer function model of the system to simulate transient effects such as load dumps.

\section{Closed-Loop Control}

Fig. 21 shows a block diagram of a possible closed-loop controller for the inverterless alternator. The alternator output voltage is compared with a reference voltage. The resultant error is fed to a proportional-integral (PI) controller that controls the duty cycle. For a faster dynamic response, a feedforward loop based on the output load current can be used. Overvoltage protection can also be implemented in the controller. This could activate an auxiliary switch to short the alternator output if the output voltage rises to unacceptable levels.

\section{E. Simulation Results}

A dynamic simulation of the alternator with a closed-loop feedback controller was developed, which adjusted the duty cycle proportionally to the output voltage error. The alternator was modeled as an adjustable constant current source with a frequency response described by the $s$-domain transfer function derived previously.

Fig. 22 shows simulation results demonstrating the rapid response of the controller to step changes in the load current. The current drawn by the load is initially $18 \mathrm{~A}(3.6 \mathrm{~kW})$. At $t=0.5 \mathrm{~s}$, the load current drops to $3.6 \mathrm{~A}(720 \mathrm{~W})$. The surplus current supplied by the alternator causes the output voltage to start rising. This is detected by the controller, which quickly increases the duty cycle. The finite response time of the alternator to the change in duty cycle means that the alternator output current does not respond instantly but takes several milliseconds to fall. Meanwhile, the output voltage continues to rise and the duty cycle becomes clamped at $100 \%$. After about $4 \mathrm{~ms}$, the alternator current has dropped below $3.6 \mathrm{~A}$, and the output voltage begins to fall. Within $23 \mathrm{~ms}$, the alternator output voltage and current have stabilized, with the alternator supplying 3.6 A and the controller operating at a higher duty cycle.
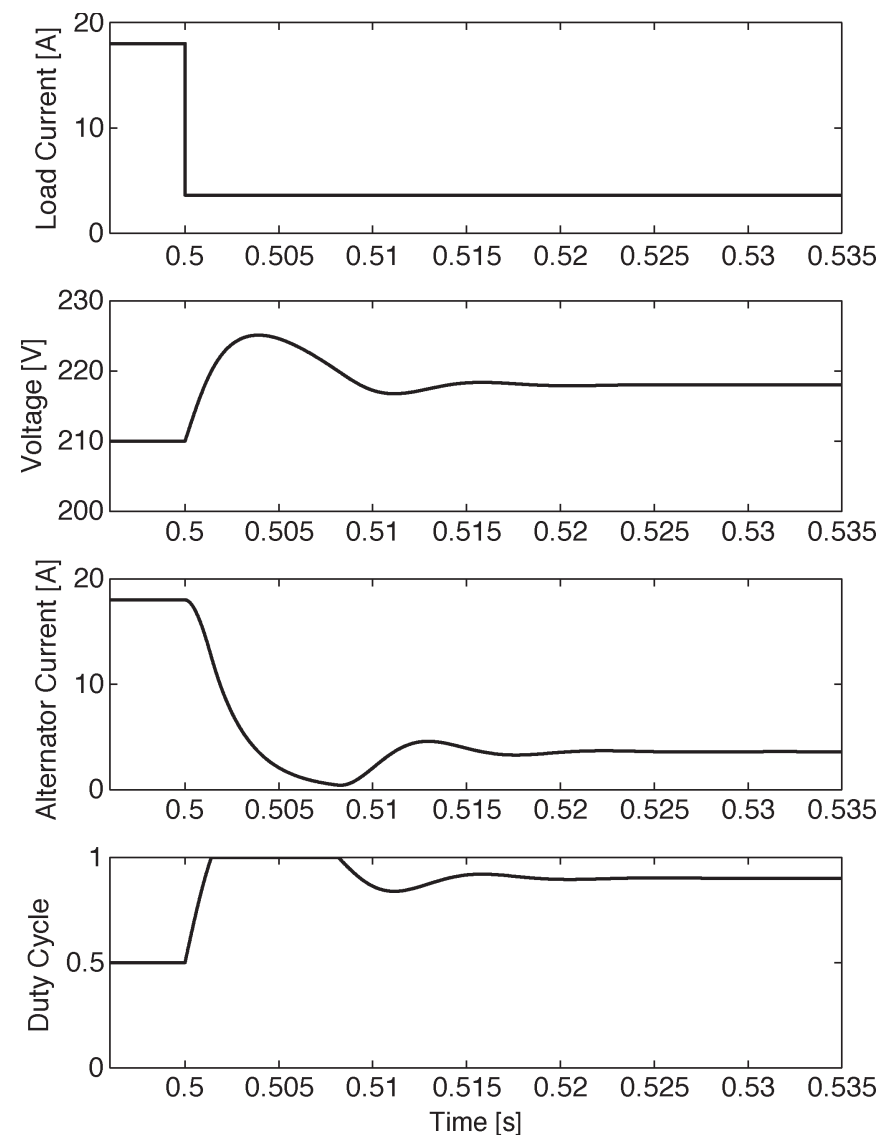

Fig. 22. Simulated transient response of the inverterless alternator closedloop controller to a load dump of 18-3.6 A (corresponding to an output power change from 3.6 to $0.7 \mathrm{~kW})$, applied at $0.5 \mathrm{~s}$.

The fast response time of the SMR allows it to limit the peak dc-link voltage rise during the transient to less than $10 \%$.

\section{CONCLUSION}

This paper has investigated the performance and control of an inverterless high-power interior PM alternator. The main advantages of the inverterless concept are the potential for wide constant power speed range, reduced number of switches and simpler control, which, ideally, does not require speed or position sensors.

Open-loop tests were performed on a 6-kW concept demonstrator machine with an SMR. The key results are enumerated as follows.

1) The dc output power of the inverterless alternator is $2.8 \mathrm{~kW}$ at an alternator speed of $1800 \mathrm{r} / \mathrm{min}, 4 \mathrm{~kW}$ at $2400 \mathrm{r} / \mathrm{min}$, and $6.6 \mathrm{~kW}$ at $6000 \mathrm{r} / \mathrm{min}$.

2) The alternator shows poor light load efficiency. This is inherent in the inverterless concept due to the high stator currents and hence high copper losses under all operating conditions including light loads. The light-load efficiency can be improved by oversizing the alternator to reduce the full-load copper losses.

3) The alternator's efficiency improves rapidly with increasing load and the full-load system efficiency reaches a maximum of $85 \%$ at $3000 \mathrm{r} / \mathrm{min}$. 
4) The alternator's measured iron loss under fieldweakening (short-circuit) conditions is significantly larger than the open-circuit iron losses. This is likely to be due to high frequency flux density harmonics under fieldweakening operation. The high iron loss results in the significant reduction of the full-load machine efficiency with increasing speed.

5) At higher speeds, the output current and power of the SMR is linearly related to the duty cycle and is independent of speed. This should allow the use of a simple feedback control algorithm to regulate the dc output voltage.

6) At low speeds, the maximum output power is obtained by limiting the minimum duty cycle. This can be implemented by setting the minimum duty cycle as a linear function of speed or by limiting the minimum input current of the switch to a fixed value.

Future work should include implementation and testing of closed-loop control for the alternator and SMR, optimizing the machine electromagnetic and mechanical design for improved efficiency and speed capability, and examination of additional control circuitry to prevent overvoltages under fault conditions.

\section{ACKNOWLEDGMENT}

The authors thank the staff of the School of Electrical and Electronic Engineering's mechanical workshop at the University of Adelaide for the technical support during the experimental testing.

\section{REFERENCES}

[1] E. C. Lovelace, "Optimization of a magnetically saturable interior permanent-magnet synchronous machine drive," Ph.D. dissertation, Dept. Elect. Eng. Comput. Sci., MIT, Cambridge, MA, Jun. 2000.

[2] D. J. Perreault and V. Caliskan, "Automotive power generation and control," IEEE Trans. Power Electron., vol. 19, no. 3, pp. 618-630, May 2004.

[3] J. M. Rivas, D. J. Perreault, and T. Keim, "Performance improvement of alternators with switched-mode rectifiers," IEEE Trans. Energy Convers., vol. 19, no. 3, pp. 561-568, Sep. 2004.

[4] W. L. Soong and N. Ertugrul, "Inverterless high power interior permanent magnet automotive alternator," IEEE Trans. Ind. Appl., vol. 40, no. 4, pp. 1083-1091, Jul./Aug. 2004.

[5] T. M. Jahns and V. Caliskan, "Uncontrolled generator operation of interior PM synchronous machines following high-speed inverter shutdown," IEEE Trans. Ind. Appl., vol. 35, no. 6, pp. 1347-1357, Nov./Dec. 1999.

[6] C. Z. Liaw, W. L. Soong, B. A. Welchko, and N. Ertugrul, "Uncontrolled generation in interior permanent magnet machines," IEEE Trans. Ind. Appl., vol. 41, no. 4, pp. 945-954, Jul/Aug. 2005.

[7] V. Caliskan, D. J. Perreault, T. M. Jahns, and J. G. Kassakian, "Analysis of three-phase rectifiers with constant-voltage loads," IEEE Trans. Circuits Syst., vol. 50, no. 9, pp. 1220-1225, Sep. 2003.

[8] V. Zivotic-Kukolj, W. L. Soong, and N. Ertugrul, "Iron loss reduction in an interior PM automotive alternator," in Conf. Rec. 40th IEEE Industry Applications Society Annu. Meeting, Hong Kong, 2005, vol. 3, pp. 1736-1743.

[9] D. M. Whaley, W. L. Soong, and N. Ertugrul, "Extracting more power from the lundell car alternator," presented at the Australasian Univ. Power Eng. Conf. (AUPEC), Brisbane, Australia, 2004.

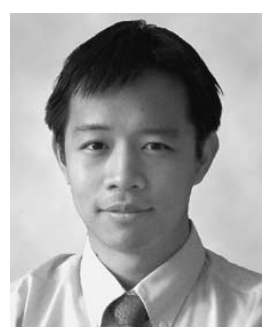

Chong-Zhi Liaw (S'04) received the B.Eng. degree with honors in computer systems engineering from the University of Adelaide, Adelaide, Australia, in 2003. He is currently working toward the Ph.D. degree at the University of Adelaide, where he is working on a low-cost wide-speed-range high-power automotive alternator.

His present research interests include permanentmagnet machines and control systems.

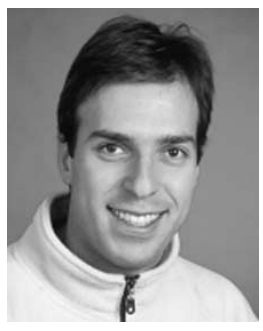

of Engineers Australia (IEAust)

David M. Whaley (S'04) received the B.E. degree with honors in electrical and electronic engineering from the University of Adelaide, Adelaide, Australia, in 2004. He is currently working toward the $\mathrm{Ph} . \mathrm{D}$. degree at the University of Adelaide, where he is working on low-cost small-scale wind power generation.

His research interests include renewable energy, grid-connected energy systems, and electrical machines.

Mr. Whaley is a Graduate Member of the Institute

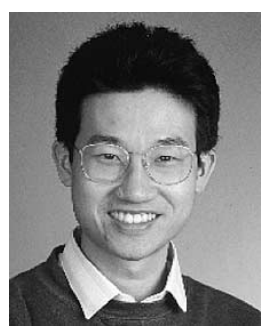

Wen L. Soong (S'89-M'94) was born in Kuala Lumpur, Malaysia. He received the B.Eng. degree from the University of Adelaide, Adelaide, Australia, in 1989, and the Ph.D. degree from the University of Glasgow, Glasgow, U.K., in 1993.

He worked for four years as an Electrical Engineer in the Power Controls Program at General Electric Corporate Research and Development, Schenectady, NY, before taking up a teaching position in the Electrical and Electronic Engineering Department at the University of Adelaide in 1998. His present research interests include permanent-magnet and reluctance machines, renewable energy generation, magnetic levitation, and condition monitoring and diagnostics.

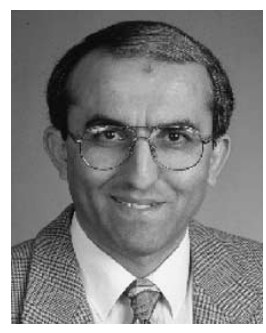

Nesimi Ertugrul (M'95) received the B.Sc. and M.Sc. degrees in electrical and in electronic and communication engineering from the Istanbul Technical University, Istanbul, Turkey, in 1985 and 1989, respectively, and the Ph.D. degree from the University of Newcastle upon Tyne, Newcastle upon Tyne, U.K., in 1993.

$\mathrm{He}$ has been with the University of Adelaide, Adelaide, Australia, since 1994, where he is a Senior Lecturer. His primary research topics include sensorless operation of switched motors, fault-tolerant motor drives, condition monitoring, and electric vehicles. He is the author of the book LabVIEW for Electric Circuits, Machines, Drives and Laboratories (Prentice-Hall, 2002).

Dr. Ertugrul serves on the Editorial Advisory Board for the International Journal of Engineering Education (IJEE). 